\title{
Use of multiplex PCR for diagnosis of bacterial infection respiratory mixed
}

\author{
Al-ssum, R. M.* and Al-Malki, M. A. A. \\ King Saud University, College of Science Department of Botany and Microbiology, \\ P.O. BOX 2455, Riyadh 11451, Saudi Arabia. \\ Email: oshair@yahoo.com
}

Received 6 March 2009; received in revised form 11 May 2009; accepted 19 May 2009

\begin{abstract}
Atypical bacteria grow very slowly in culture or they do not grow at all leading to delays in detection and diagnosis. PCR multiplex was performed on template DNAs extracted from seventy three collected specimens. Thirty seven showed positive indication for the presence of bacterial infection. The incidence of Mycoplasma pneumoniae, Chlamydia pneumonia and Legionella pneumophila as a single infecting agent was $31.5 \%, 27.5 \%$ and $20 \%$ respectively. Dual agent infection caused by Mycoplasma + Chlamydia, Mycoplasma + Legionella and Legionella + Chlamydia was $24 \%$, $20 \%$ and $15 \%$ respectively. Triple agent infection caused by Legionella + Mycoplasma + Chlamydia was $17.5 \%$. The etiology of the infection was M. pneumoniae, L. pneumophila or C. pneumoniae as a single etiology or in combination of two or three organisms.
\end{abstract}

Keywords: Chlamydia pneumonia, Epidemiology, Legionella pneumophila, Mycoplasma pneumoniae

\section{INTRODUCTION}

Acute upper respiratory infections (URI) usually benign, transitory self limited, but it could be serious disease in children and young infants (Phares et al., 2007). Infection of the lower respiratory tract, especially pneumonia, can be severe or fatal. Atypical bacteria (Mycoplasma, Legionella and Chlamydia) are the dominant pathogens; accounting for much higher percentage of lower than upper respiratory tract infections (Welti et al., 2003). Lower respiratory tract infections (LRTIs) continue to be important cause of community-acquired pneumonia and therapy is largely empiric because of the inability to determine the causative microorganisms of most patients by the time treatment is initiated (Elkholy et al., 2009).

The classical microbiological identification techniques can not provide an efficient means of diagnosis because most of the atypical bacteria grow either slowly or not at all in culture, leading to delays in detection and diagnosis (Sung et al., 2006). These problems lead to the emergence of other diagnostic methods, such as L. pneumophila antigen, serologic testing by microimmunofluorescence or compliment fixation assays and indirect immuno-enzyme assay (ELISA) which also demonstrated a lack of sensitivity and specificity (Kumar et al., 2007; Elkholy et al., 2009). Thereafter, nucleic acid amplification based techniques have been developed to diagnose the infections caused by these pathogens (Reinhard et al., 2005). Such PCR assays have lessened the importance of culture as means for detecting $M$. pneumoniae, L. pneumophila and $C$. pneumoniae; showing a sensitivity greater than culture (Matsukura et al., 2004).
Multiplex PCR assay was developed to detect $M$. pneumoniae, L. pneumophila and $C$. pneumonia (Kate et al., 2003). This study has been designed to investigate and evaluate the incidence of single, dual and multiple respiratory bacterial infections using PCR multiplex.

\section{MATERIALS AND METHODS}

\section{Materials}

A total of 236 clinical specimens (118 males, 118 females) were obtained from King Saud Chest Hospital (Sahari Hospital) in Riyadh city. The sample volume was $7,000 \mu \mathrm{L}$ to $1,000 \mu \mathrm{L}$, types of samples were from pleural fluid (which have been taken in accordance with patients permission). The specimens for immediate treatment were stored at $4{ }^{\circ} \mathrm{C}$; others at $-20{ }^{\circ} \mathrm{C}$. Qiagen DNA minikit protocol was followed to prepare the reagents. QIAGEN Protease stock solution was stored at $2-8{ }^{\circ} \mathrm{C}$. A $5.5 \mathrm{~mL}$ protease solvent was pipetted into the vial containing lyophilized QIAGEN. AL buffer was stored at room temperature, $15-25{ }^{\circ} \mathrm{C}$, it was mixed thoroughly by shaking before use. An appropriate amount of ethanol (96-100\%) was added to buffer AW1 and AW2 before use and stored at room temperature.

\section{Sample Processing}

A $200 \mu \mathrm{L}$ of each sample was pipetted into a $1.5 \mathrm{~mL}$ micro centrifuge tube. A $1000 \mu \mathrm{L}$ of phosphate buffer saline (PBS) was added and mixed by vortexing for $10 \mathrm{~s}$ and centrifuged at $14,000 \mathrm{rpm}$ for $15 \mathrm{~s}$. The supernatant was 
discarded and the pellet was resuspended in $200 \mu \mathrm{L}$ of PBS and mixed by vortexing for $15 \mathrm{~s}$.

\section{DNA extraction}

A $20 \mu \mathrm{L}$ protease was pipetted into the bottom of a $1.5 \mathrm{~mL}$ microcentrifuge tube containing $200 \mu \mathrm{L}$ of sample and 200 $\mu \mathrm{L} A \mathrm{~L}$ buffer was added to the sample. This was followed by pulse-vortexing for $15 \mathrm{~s}$. The sample was then incubated at $56^{\circ} \mathrm{C}$ for $10 \mathrm{~min}$ and centrifuged briefly. A $200 \mu \mathrm{L}$ ethanol (96-100\%) was added, vortexed for $15 \mathrm{~s}$. The $1.5 \mathrm{~mL}$ microcentrifuge tube was briefly centrifuged to remove drops from the inside of the lid. The mixture was carefully applied to the QIAamp Mini spin column, in a 2 $\mathrm{mL}$ collection tube, centrifuged at $6,000 \times \mathrm{g}$ ) for $1 \mathrm{~min}$. The QIAamp Mini spin column was placed in a clean $2 \mathrm{~mL}$ collection tube and the tube containing the filtrate was discarded. A $500 \mu \mathrm{L}$ AW1 buffer was added, centrifuged at $(6000 \times g)$ for $1 \mathrm{~min}$., $500 \mu \mathrm{L}$ AW2 buffer was added, centrifuged at full speed $(20,000 \times g)$ for $3 \mathrm{~min}$. The QIAamp Mini spin column was placed in a clean $1.5 \mathrm{~mL}$ microcentrifuge tube and the collection tube containing the filtrate was discarded. The QIAamp Mini spin column was opened, $200 \mu \mathrm{L}$ of $\mathrm{AE}$ buffer was added, incubated at room temperature for $1 \mathrm{~min}$, and then centrifuged at $(6,000 \times g)$ for $1 \mathrm{~min}$. To increase the yield of the eluted DNA, further incubation at room temperature for $5 \mathrm{~min}$ and re-elution of the first yield was necessary. The DNA was concentrated with isopropanol and ammonium acetate and washed with $200 \mu \mathrm{L}$ of $75 \%$ ethanol, evaporated by incubating at $65{ }^{\circ} \mathrm{C}$ for $5 \mathrm{~min}$ and dissolved in $10 \mu \mathrm{L}$ deionized water.

Primers and standard control organism were purchased from Maxim Biotech. Inc. USA. Primers sequences are as follow:

5'-GTTGTTCATGAAGGCCTACT-3' forward 5'-TGCATAACCTACGGTGTGTT-3' reverse 5'-ACCGATGCCACATCATT-3' forward 5'-ACGACCAGTGTATTCGACAG-3' reverse 5'-TCAATCTGGCGTGGATCTCT-3' forward 5'-GTCACTGGTTAAACGGACTA-3' reverse

\section{Multiplex PCR profile}

\section{Reaction volume}

A $25.0 \mu \mathrm{L}, 2 x$ PCR buffer, $5.0 \mu \mathrm{L} 10 x$ primers, $0.5 \mu \mathrm{L}$ Taq polymerase $(5 \mathrm{U} / \mu \mathrm{L}), 5.0 \mu \mathrm{L}$ DNA, $14.5 \mu \mathrm{L} \mathrm{H}_{2} \mathrm{O}$, total volume $50 \mu \mathrm{L}$.

\section{PCR Program}

$94^{\circ} \mathrm{C}, 2 \mathrm{~min}$ for 1 cycle, $96^{\circ} \mathrm{C}, 1.30 \mathrm{~min}$ for 2 cycles, 63 ${ }^{\circ} \mathrm{C}, 4 \mathrm{~min}$ for 2 cycle, $\left(94^{\circ} \mathrm{C}, 1.30 \mathrm{~min}, 62^{\circ} \mathrm{C}, 2.30 \mathrm{~min}\right.$ for 35 cycles), $70^{\circ} \mathrm{C}, 10 \mathrm{~min}$ for 1 cycle and $4^{\circ} \mathrm{C}$ for cooling. Agarose gel electrophoresis was used to visualize multiplex PCR DNA product and photographed under UV.

\section{RESULTS AND DISCUSSION}

Thirty seven out of seventy three specimens showed positive indication for the presence of bacterial infection. The incidence of $M$. pneumoniae, $C$. pneumonia, $L$. pneumophila as a single infecting agent was $31.5 \%$, $27.5 \%$ and $20 \%$ respectively. Dual agent infection caused by Mycoplasma + Chlamydia, Mycoplasma + Legionella and Legionella + Chlamydia was $24 \%, 20 \%$ and $15 \%$ respectively. Triple agent infection caused by Legionella + Mycoplasma + Chlamydia was $17.5 \%$. The etiology of the infection was $M$. pneumoniae, L. pneumophila and $C$. pneumoniae as a single etiology or in combination of two or three organisms was positive for HIV infection. The multiplex PCR results are presented in Figure 1 and detailed in Table 1. Figure 2 presents the percentage of patients infected by single and multiple agents. $M$. pneumoniae is one of the causative agents of atypical community-acquired pneumoniae (Salvatore et al., 2009). However, it is associated with the aggregate number of chronic infectious burden of atypical respiratory pathogens such as $C$. pneumonia, $M$. pneumoniae and $L$. pneumophila.

Multiple studies have suggested an association between $C$. pneumoniae and $M$. pneumoniae infection and cardiovascular disease (Ngeh et al., 2005). Respiratory tract infections account more than $10 \%$ of all office visit to the primary care physician and restrict the activities of children in certain age category (5-17 years) due to acute condition (Phares et al., 2007). On the other side community acquired pneumonia is the sixth leading cause of death and $25 \%$ of patients are requiring hospitalization (Nawalutfiyya et al., 2006). Mortality among patients with CAP has risen due in part to an increasing elderly population (Liu et al., 2004). A typical pneumonia caused by $C$. pneumoniae, $M$. pneumoniae and $L$. pneumophila as a single agent or mixed infection has been detected in $50.68 \%$ of all selected and studied specimens. It is an alarming situation which should be taken seriously by health care system management and the search for tools and measures to reduce such high percentage of infection is a necessity. The question which should be raised concerning this observation, are Saud's citizen more susceptible to pneumonia infection or it is the inadequate management within the hospital or even both. Unfortunately we do not have the answer without investigating each part of the question.

However, we care for the patients because the treatments for $M$. pneumoniae, $C$. pneumoniae and $L$. pneumophila as a single infecting agent may be achievable but, when the disease is a result of mixed infection it is hard to treat in the absence of knowledge about the etiological agent. In mixed infection treatments of a single agent may be inhibited and decrease the number and activity of the organism leading to the improvement of the patient. By contrast, due to inhibition of one organism the other may thrive causing the onset of new suffering period and so on. Death has been observed among hospitalized patients but our conclusion was hindered by an underling disease e.g. TB and HIV. 
Mal. J. Microbiol. Vol 6(1) 2010, pp. 1-6
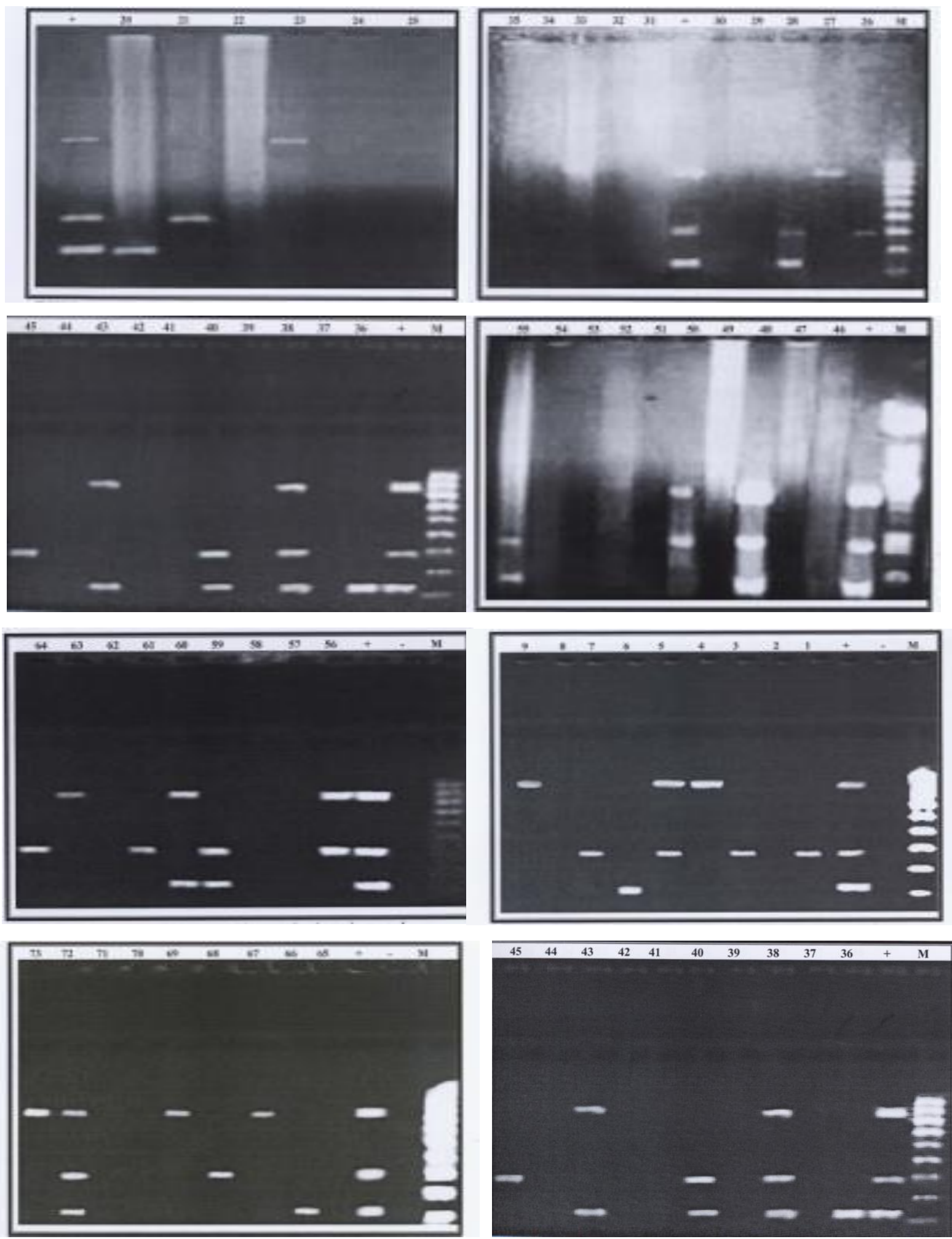

Figure 1: Multiplex PCR results of patients showing single, double and triple infection. Lane M: Marker; Lane (+): Positive control; Lane 36: Legionella; Lane 38: Mycoplasma, Legionella and Chlamydia; Lane 40: Mycoplasma and Legionella; Lane 43: Legionella and Chlamydia; Lane 45: Mycoplasma 
Mal. J. Microbiol. Vol 6(1) 2010, pp. 1-6

Table 1: Interpretation of multiplex PCR results

\begin{tabular}{|c|c|c|c|c|c|}
\hline Patients & Nationality & Prediagnosing & $\begin{array}{l}\text { Mycoplasma } \\
\text { pneumoniae }\end{array}$ & $\begin{array}{c}\text { Legionalla } \\
\text { pneumophila }\end{array}$ & $\begin{array}{l}\text { Chlamydia } \\
\text { pneumonia }\end{array}$ \\
\hline 1 & Saudi & Resp & + & - & - \\
\hline 2 & Saudi & TB & - & - & - \\
\hline 3 & Saudi & Resp & + & - & - \\
\hline 4 & Saudi & Resp & - & - & - \\
\hline 5 & Saudi & TB & + & - & + \\
\hline 6 & Saudi & Resp & - & + & - \\
\hline 7 & Saudi & Resp & + & - & - \\
\hline 8 & Saudi & Resp & - & - & - \\
\hline 9 & Saudi & Resp & - & - & + \\
\hline 10 & Saudi & Reasp & + & + & - \\
\hline 11 & Saudi & Reasp & - & - & - \\
\hline 12 & Saudi & TB & - & - & + \\
\hline 13 & Saudi & Reasp & + & - & - \\
\hline 14 & Saudi & TB & + & - & + \\
\hline 15 & Saudi & Reasp & - & - & - \\
\hline 16 & Saudi & Reasp & + & + & - \\
\hline 17 & Saudi & TB & - & - & - \\
\hline 18 & Saudi & Reasp & - & - & - \\
\hline 19 & Saudi & Reasp & - & - & + \\
\hline 20 & Saudi & TB & - & + & - \\
\hline 21 & Saudi & TB & + & - & - \\
\hline 22 & Saudi & Reasp & - & - & - \\
\hline 23 & Saudi & Reasp & - & - & + \\
\hline 24 & Saudi & TB & - & - & - \\
\hline 25 & Saudi & Reasp & - & - & - \\
\hline 26 & Saudi & Reasp & + & - & - \\
\hline 27 & Saudi & TB & - & - & + \\
\hline 28 & Saudi & Reasp & + & + & - \\
\hline 29 & Saudi & Reasp & - & - & - \\
\hline 30 & Saudi & TB & - & - & - \\
\hline 31 & Saudi & Reasp & - & - & - \\
\hline 32 & Saudi & Reasp & - & - & - \\
\hline 33 & Saudi & Reasp & - & - & + \\
\hline 34 & Saudi & Reasp & - & - & - \\
\hline 35 & Saudi & Reasp & - & - & - \\
\hline 36 & Saudi & Reasp & - & + & - \\
\hline 37 & Saudi & TB & - & - & - \\
\hline 38 & Saudi & HIV+ Resp & + & + & + \\
\hline 39 & Saudi & Reasp & - & - & - \\
\hline 40 & Saudi & TB & + & + & - \\
\hline 41 & Saudi & Reasp & - & - & - \\
\hline 42 & Saudi & Reasp & - & - & - \\
\hline 43 & Saudi & Reasp & - & + & + \\
\hline 44 & Saudi & TB & - & - & - \\
\hline 45 & Saudi & Reasp & + & - & - \\
\hline 46 & Saudi & TB & - & - & - \\
\hline 47 & Saudi & Reasp & - & - & - \\
\hline 48 & Saudi & TB & + & + & + \\
\hline 49 & Saudi & TB & - & - & - \\
\hline 50 & Saudi & Reasp & + & - & + \\
\hline 51 & Saudi & Reasp & - & - & - \\
\hline 52 & Saudi & Reasp & - & - & - \\
\hline 53 & Saudi & Reasp & - & - & - \\
\hline 54 & Saudi & Reasp & - & - & - \\
\hline 55 & Saudi & Reasp & + & + & - \\
\hline 56 & Saudi & Reasp & + & - & + \\
\hline 57 & Saudi & Reasp & - & - & - \\
\hline 58 & Saudi & Reasp & - & - & - \\
\hline 59 & Saudi & HIV & + & + & - \\
\hline 60 & Saudi & TB & - & + & + \\
\hline
\end{tabular}




$\begin{array}{llllll}61 & \text { Saudi } & \text { Reasp } & + & - & - \\ 62 & \text { Saudi } & \text { TB } & - & - & - \\ 63 & \text { Saudi } & \text { Reasp } & - & - & - \\ 64 & \text { Saudi } & \text { Reasp } & + & - & - \\ 65 & \text { Saudi } & \text { Reasp } & - & + & + \\ 66 & \text { Saudi } & \text { Reasp } & - & - & - \\ 67 & \text { Saudi } & \text { Reasp } & - & - & + \\ 68 & \text { Saudi } & \text { TB } & + & - & - \\ 69 & \text { Saudi } & \text { TB } & - & - & - \\ 70 & \text { Saudi } & \text { Reasp } & - & - & + \\ 71 & \text { Saudi } & \text { TB } & - & + & + \\ 72 & \text { Saudi } & \text { Reasp } & + & - & + \\ 73 & \text { Saudi } & \text { Reasp } & - & & \end{array}$

However, we conclude that the use of such multiplex PCR systems would improve the management of adult patients with M. pneumoniae, C. pneumonia and L. pneumophila related to nosocomial respiratory bacterial infections. Such molecular assay would be also valuable particularly with regard to disease control. Moreover, the single, dual and triple etiology of genetically distinct organisms indicates the possibility of repeated respiratory infections.

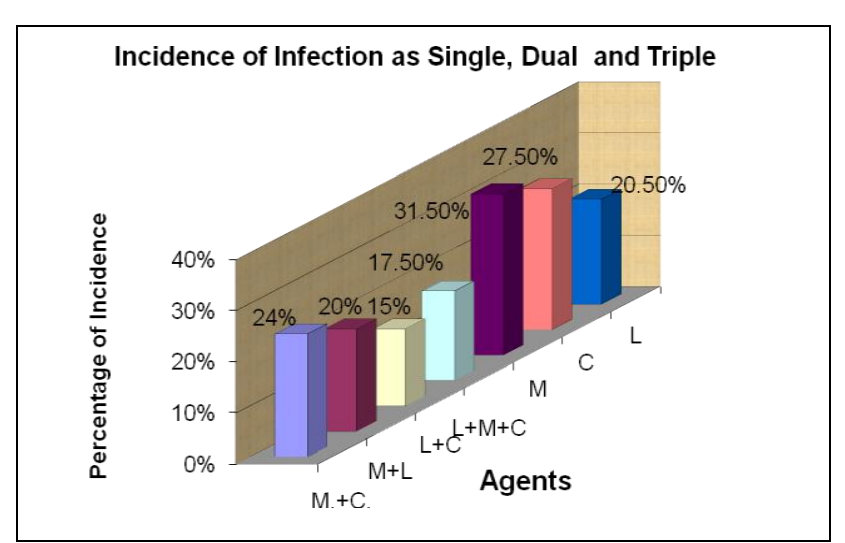

Figure 2: Percentage of patients infected by single and multiple agent

\section{REFERENCES}

Elkholy, A., Elkaraksy, H., Fattouh, A., Bazaraa, H., Hegazy, R. and AbdEIhalim, M. (2009). Acute lower respiratory tract infection due to Chlamydia and Mycoplasma sp. in Egyptian children under 5 years of age. Journal of Tropical Pediatrics 55, 195-197.

Kate, E., Templeton, S. A., Scheltinga, A. and Graffelman, W. (2003). Comparison and evaluation of real-time PCR, realtime nuclei acid sequence based amplification, conventional PCR and serology for diagnosis of Mycoplasma pneumoniae. Journal of Clinical Microbiology 41, 4366-4371.

Kumar, R., Surendran, P. K. and Thampuran, N. (2007). Evaluation of culture, ELISA and PCR assays for the detection of Salmonella in seafood. Applied Microbiology 46, 221-226.
Liu, Y. N., Zhao, T. M., Yao, W. Z., Zhang, L. S., He, Z. Y., Jiao, Y. M., Duan, Y. Y., Nie, Z. S. and Wang, R. L. (2004). Prevalence of atypical pathogens in adult patients with community-acquired pneumoniae in Beijing. Zhonghua Jie He He Hu Xi Za Zhi 27, 27-30.

Matsukura, Tajiri, T., Kato, S., Togashi, A., Masuda, G., Tokunaga, A. and Yamada, N. (2004) Diagnostic value of culture, histology and PCR for Helicobacter pylori in the remnant stomach after surgery. Blackwell Publishing Ltd. 6, 33- 38.

Nawalutfiyya, M., Henley, E. and Lindaf, C. G. (2006). Diagnosis and treatment of community-acquired Pneumoniae. Journal of American Family Physician 73, 442-450.

Ngeh, J. and Goodbourn, C. (2005). Chlamydia pneumoniae, Mycoplasma pneumoniae, and Legionella pneumophila in elderly patients with stroke (C-PEPS, M-PEPS, L-PEPSA case-control study on the infectious burden of a typical respiratory pathogens in elderly patients with acute cerebrovascular disease. Stroke 36, 259-265.

Phares, C. R., Wangroongsarb, P., Chantra, S., Paveenkitiporn, W., Tondella, M. L., Benson, R. F., Thacker, W. L., Fields, B. S., Moore, M. R., Fischer, J., Dowell, S. F. and Olsen, S. J. (2007). Epidemiology of severe pneumoniae caused by Legionella longbeachae, Mycoplasma pneumoniae, and Chlamydia pneumoniae. Clinical Infectious Diseases 45, 145-155.

Reinhard B. Raggam, Eva Leitner, Jörg Berg, Gerhard Mühlbauer, Egon Marth and Harald H. Kessler (2005). Single-run, parallel detection of DNA from three pneumoniae producing bacteria by realtime polymerase chain reaction. Journal of Molecular Diagnostic 7,133-138.

Salvatore, C. M., Techasaensiri, C., Tagliabue, C., Katz, K., Leos, N., Gomez, A. M., McCracken, G. H. and Hardy, R. D. (2009). Tigecycline therapy significantly reduces the concentrations of inflammatory pulmonary cytokines and chemokines in a murine model of Mycoplasma pneumoniae. Antimicrobial Agents and Chemotherapy 53, 15461551. 
Sung, H., Kang, S. H., Bae, Y. J., Hong, J. T., Chung, Y. B., Lee, S. K. and Song, S. (2006). PCR-based detection of Mycoplasma sp. Journal of Microbiology 44, 42-49.

Welti, M., Jaton, K., Altwegg, M., Sahli, R., Wenger, A. and Bille, J. (2003). Development of a multiplex realtime quantitative PCR assay to detect Chlamydia pneumoniae, Legionella pneumophila and Mycoplasma pneumoniae in respiratory tract secretions. Diagnostic Microbiology and Infectious Disease 45, 85-95. 